\title{
Kicking the habit of routine preoperative laboratory testing in children undergoing cardiac surgery
}

\author{
Andrew J. Lodge, MD
}

\footnotetext{
From the Division of Thoracic and Cardiovascular Surgery, Department of Surgery, Duke University Medical Center, Durham, NC.

Disclosures: Author has nothing to disclose with regard to commercial support.

Received for publication Oct 24, 2016; accepted for publication Oct 27, 2016; available ahead of print Dec 16, 2016.

Address for reprints: Andrew J. Lodge, MD, Division of Thoracic and Cardiovascular Surgery, Department of Surgery, Duke University Medical Center, Durham, NC 27710 (E-mail: Andrew.lodge@ duke.edu).

J Thorac Cardiovasc Surg 2017;153:686-7

$0022-5223 / \$ 36.00$

Copyright $(2) 2016$ by The American Association for Thoracic Surgery

http://dx.doi.org/10.1016/j.jtcvs.2016.10.062
}

In their article in this issue of the Journal, "Routine Preoperative Laboratory Testing in Elective Pediatric Cardiothoracic Surgery is Largely Unnecessary," ${ }^{1}$ Nieto and colleagues have provided us with a formal look at the process of preoperative evaluation in this population. Although their review was retrospective and involved only a single center, it was a large study involving more than 1000 patients. The practice of ordering preoperative routine laboratory testing (RLT) is common and deeply ingrained. It is instilled in us during training and passed on from generation to generation; however, it is a practice that has been poorly studied. During my own training, I remember having a checklist of studies to order for each preoperative patient that very closely resembles the list that Nieto et al ${ }^{1}$ describe in their article. I never questioned the practice and diligently followed up on all of the studies; however, that was at a time when essentially all of the patients were admitted to the hospital before elective surgery. That custom has been abandoned, yet we cling to RLT for unclear reasons.

Recently, studies evaluating the process and efficacy of preoperative testing in pediatric patients have begun to be published. Compared with the study by Nieto et al, ${ }^{1}$ other studies in the literature to date have not looked as comprehensively at the issue, focusing rather on specific aspects, such as blood testing. ${ }^{2}$ Interestingly, even when the tests are not found to be particularly useful, there still seems to be a reluctance to let go of the diagnostic study in question. ${ }^{3}$ The study from Nieto et $\mathrm{al}^{1}$ distinguishes itself as the first to focus on RLT in pediatric cardiac patients, which is important because those patients are arguably undergoing operations of larger magnitude and with more potential for physiologic derangement and bleeding than others. The authors' practice appears rigorous and detail-oriented, including blood tests with coagulation parameters, urinalysis, chest radiograph, and electrocardiogram. This is not, however, a standard practice, and differs significantly from our own.

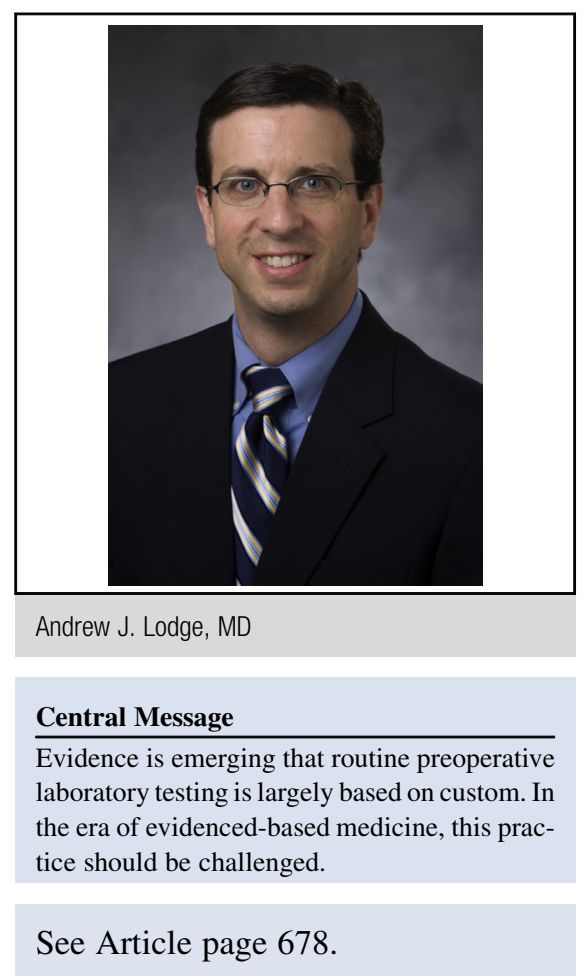

Given the above, and perhaps not surprisingly, there are not good published guidelines for RLT in our specialty. In one of the most commonly used textbooks on pediatric cardiac surgery, there is little guidance on this topic. In their chapter on preoperative evaluation ${ }^{4}$ in Pediatric Cardiac Surgery by Mavroudis and Backer, the chest radiograph is touted as a useful study, the preoperative electrocardiogram is acknowledged to be generally not routinely useful, and blood test and urinalysis are not acknowledged at all. In another well-regarded text by Jonas, ${ }^{5}$ the subject of RLT is not addressed, despite the title being Comprehensive Surgical Management of Congenital Heart Disease.

All of this indicates that RLT is a subject that has not been carefully considered in the past. In today's environment of increasing medical costs and oversight, we can no longer afford to neglect this issue. Evidence-based medicine is a trendy and current catch phrase, but it is also driving a substantial amount of decision making, policy, and reimbursement. ${ }^{6}$ Based on their review and their own data, there is little to no evidence to support RLT in elective pediatric cardiac surgery. Nieto and his colleagues ${ }^{1}$ should be 
congratulated for their initial effort to evaluate this ritual. It behooves all of us to assess our own systems and adjust accordingly to more data-supported practices.

\section{References}

1. Nieto RM, De Leon LE, Trujillo Diaz D, Krauklis KA, Fraser CD Jr. Routine preoperative laboratory testing in elective pediatric cardiothoracic surgery is largely unnecessary. J Thorac Cardiovasc Surg. 2017;153:678-85.
2. Imesbah F, Mandiwanza T, Kaliaperumal C, Caird J, Crimmins D. Routine preoperative blood testing in pediatric neurosurgery. J Neurosurg Pediatr. 2013;12:615-21.

3. Bhasin N, Parker RI. Diagnostic outcome of preoperative coagulation testing in children. Pediatr Hematol Oncol. 2014;31:458-66.

4. Prieto LR, Schwartz ML, Sterba R, Arruda J, Preminger TJ. Preoperative diagnostic evaluation. In: Mavroudis C, Backer CL, eds. Pediatric Cardiac Surgery. 4th ed. Oxford, UK: Wiley-Blackwell; 2013:60-83.

5. Jonas RA, ed. Comprehensive Surgical Management of Congenital Heart Disease. 2nd ed. Boca Raton, FL: CRC Press; 2014.

6. Kronick R. AHRQ's role in improving quality, safety, and health system performance. Public Health Rep. 2016;131:229-32. 